\title{
Unintended Consequences of Coronavirus-Related Unemployment Insurance Tax Laws
}

\section{Aaron Amburgey, Research Associate}

Serdar Birinci, Economist

$s$ a result of COVID-19-related business shutdowns, U.S. initial unemployment insurance (UI) claims increased by an unprecedented 3,000 percent between March 7 and April 4-for a total of about 17 million claims during this period. In response to this historic increase in claims, the U.S federal government passed the Coronavirus Aid, Relief and Economic Security (CARES) Act. The CARES Act aims to provide relief to the unemployed by, first, relaxing the eligibility requirements of UI and, second, increasing the generosity of UI benefits. The bill relaxed eligibility requirements by permitting states to provide benefits for individuals who are unable to work due to COVID-19-related reasons and temporarily waiving worksearch requirements. Furthermore, the bill increased the generosity of benefits by increasing all claimants' checks by $\$ 600$ per week until August and extending UI benefit durations by 13 weeks.

\section{Waived employer payroll tax increases for state unemployment insurance appear to have increased layoffs.}

UI payments are funded through an employer payroll tax, which typically increases for a firm each time a worker separates from the firm and takes up UI benefits. Many states are also attempting to alleviate coronavirus-related

Figure 1

States That Have Waived Coronavirus-Related UI Tax Increases

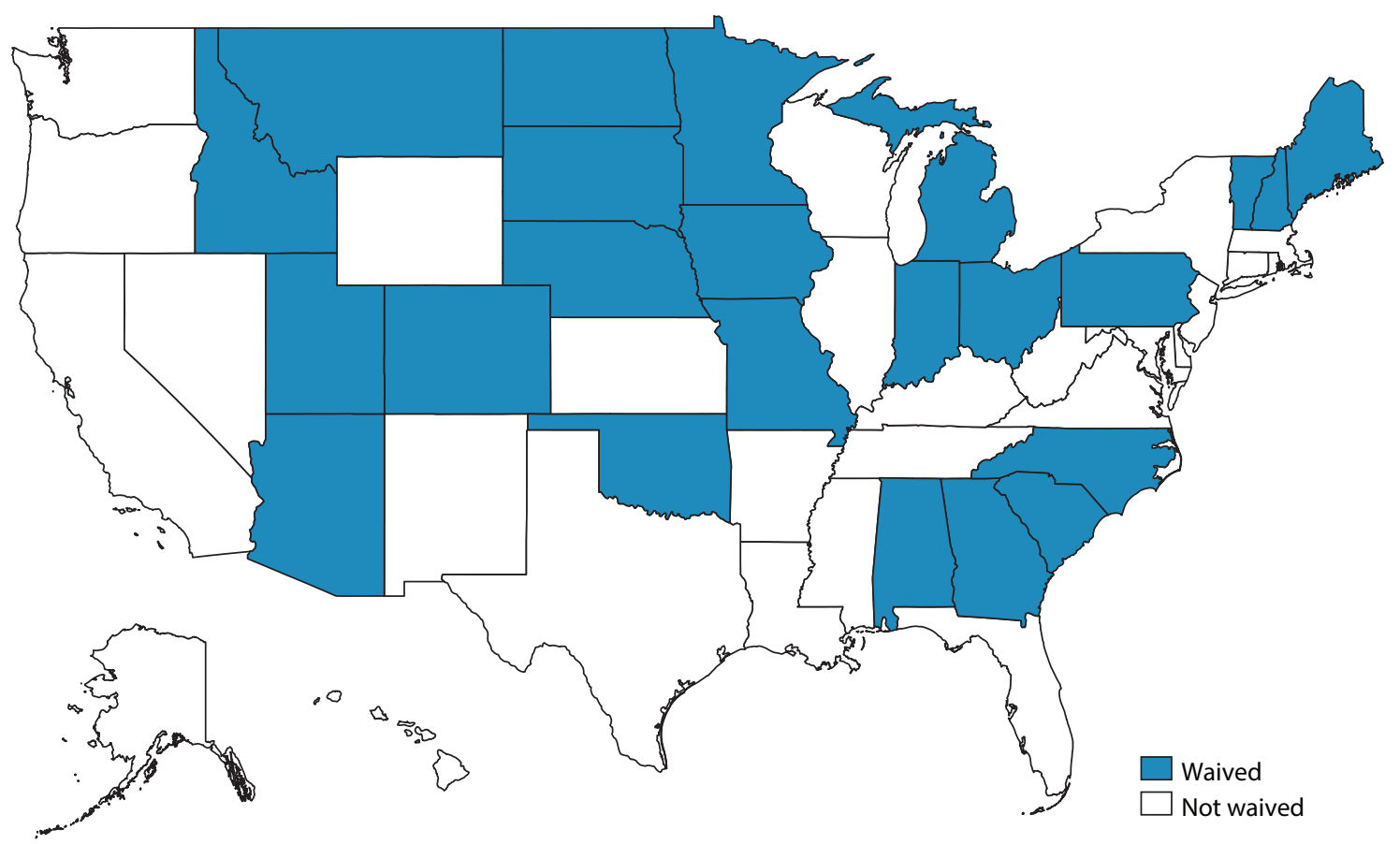

NOTE: See detailed explanations about COVID-19-related changes at each state's Department of Labor website. SOURCE: Each state's Department of Labor. 
Figure 2

Increase in Initial UI Claims from March 7 to April 4, 2020

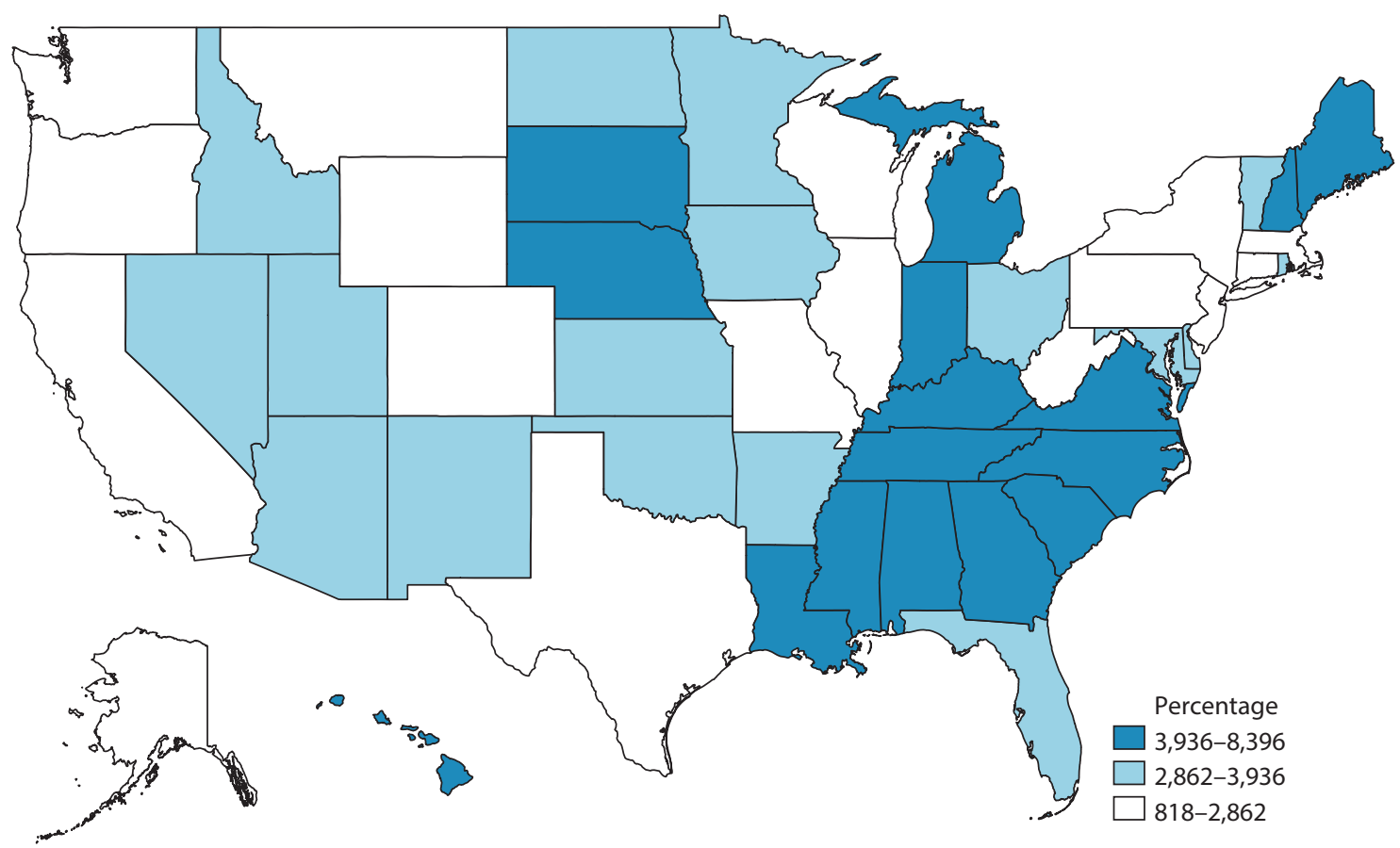

SOURCE: U.S. Department of Labor Unemployment Insurance Weekly Claims Report.

business losses by changing state-level UI tax laws. For example, Georgia, Michigan, and New Hampshire have announced plans to waive tax increases for firms whose employees file for benefits during the coronavirus pandemic, while Wyoming, Connecticut, and Oregon have not. Figure 1 indicates which states have specified these tax increases will be waived. ${ }^{1}$

However, the waivers could have an unintended consequence: Firms may be more inclined to lay off workers now given that the current cost of layoffs is being reduced. We now explore this possibility.

One way to evaluate whether these changes incentivize firms to lay off their workers is to compare last month's increase in UI claims between states which have and have not waived UI-related tax increases. If increases to UI claims during the pandemic are higher in states that have waived these taxes than in states that have not, then it is evidence that relaxing UI tax penalties is associated with firms' increased willingness to lay off more workers during the pandemic.

We first calculate each state's percentage increase in initial UI claims from March 7 to April 4. Figure 2 shows the results, with Georgia, Michigan, and New Hampshire experiencing the highest increases and Wyoming, Connecticut, and Oregon experiencing the lowest increases.

We then calculate the correlation between states' percentage increases in initial UI claims from March 7 to April 4 and whether or not they have waived employer UI tax increases for coronavirus-related unemployment. The correlation is positive (0.33). That is, the firm tax waiver is associated with an additional increase in UI claims for a state during this period. ${ }^{2}$

In conclusion, this result supports the idea that waiving UI tax rate increases has resulted in more layoffs during the first month of the coronavirus pandemic in the U.S.

\section{Notes}

${ }^{1}$ Here, we assume that states that have not specified whether they have adopted this policy are considered not to have. Indiana, New Hampshire, Ohio, and Utah will mutualize these tax increases to the entire pool of employers. We consider this a waiver, as employers who lay off workers will only be indirectly impacted.

2 In an alternative sample where we consider only states that have specified their policy, we get an even higher correlation coefficient of 0.47 . 